\title{
Mehr Ergonomie bei Strahlarbeiten
}

Eine neue Generation von Strahlanlagen lässt sich auf Knopfdruck individuell auf die gewünschte

Arbeitshöhe einstellen und soll somit ermüdungsfreies Arbeiten ermöglichen.

peziell für ein ermüdungsfreies Arbeiten hat die Firma IVR Strahltechnik mit Sitz in Hilden ein neues Strahlanlagen-Programm entwickelt. Gemeinsam sind den Strahlkabinen vom Typ Ergo die ergonomisch ausgelegten Features: Dazu gehören unter anderem die stufenlose Höhenverstellung des Arbeitsraumes. Der Spindelantrieb ermöglicht eine optimale, ermüdungsfreie Arbeitsposition für Mitarbeiter mit Körpergrößen von circa 1,60 bis $1,95 \mathrm{~m}$.

Zusätzlich erleichtern ergonomisch optimierte Eingriffsöffnungen die Arbeit. Dieses Konzept bietet vielerlei Vorzüge. Bei klassischen StandardStrahlkabinen ist die Position der Eingriffsöffnungen unveränderbar. Optimierungen der Arbeitsposition für unterschiedliche Werkstücke und Be-

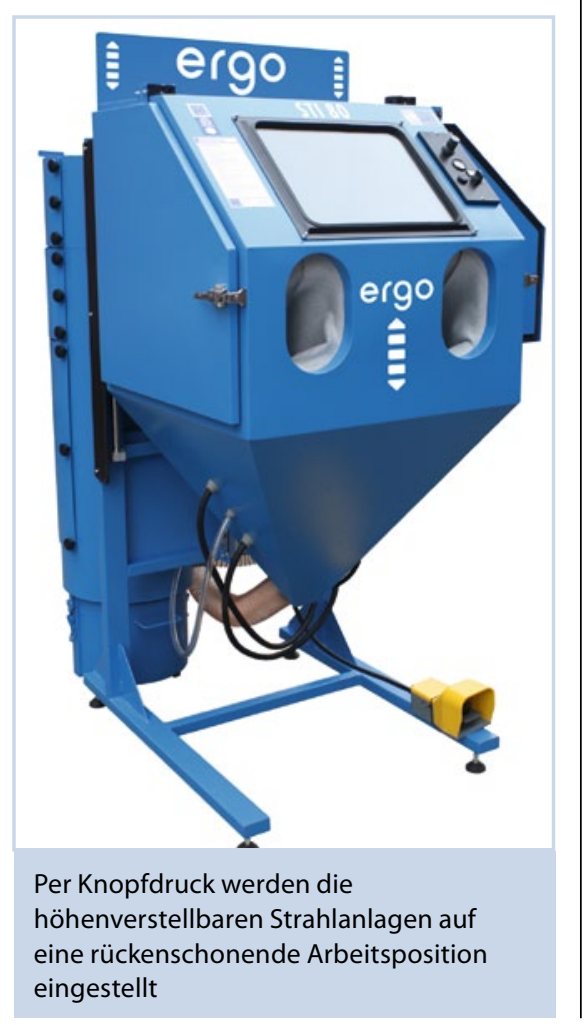

arbeitungsvorgaben sind hierbei häufig nicht möglich. Mit der neu entwickelten, höhenverstellbaren Technologie können große und kleine, leichte oder schwere Werkstücke in optimaler Weise bewegt und bearbeitet werden. Kleine Werkstücke sind ohne ermüdendes Hochhalten mit ständigem Blickkontakt zu strahlen. Schwere Teile lassen sich ohne Überlastung des Rückens im Strahlraum platzieren. Auch der Schichtwechsel verliert die personenbezogenen Risiken. Der nachfolgende
Mitarbeiter findet per Knopfdruck die für ihn optimale ermüdungsfreie und rückenschonende Arbeitsposition. Die Serienmaschinen werden in verschiedenen Strahlraumgrößen $(850 \times 800 \mathrm{x}$ $800 \mathrm{~mm}$ und $1100 \times 900 \times 900 \mathrm{~mm}, \mathrm{~B} \times$ $\mathrm{T} \times \mathrm{H})$ geliefert.

\section{Kontakt:}

IVR Strahltechnik eK, Hilden,

Tel.02103252960, info@ivr-strahltechnik.de

www.ivr-strahltechnik.de

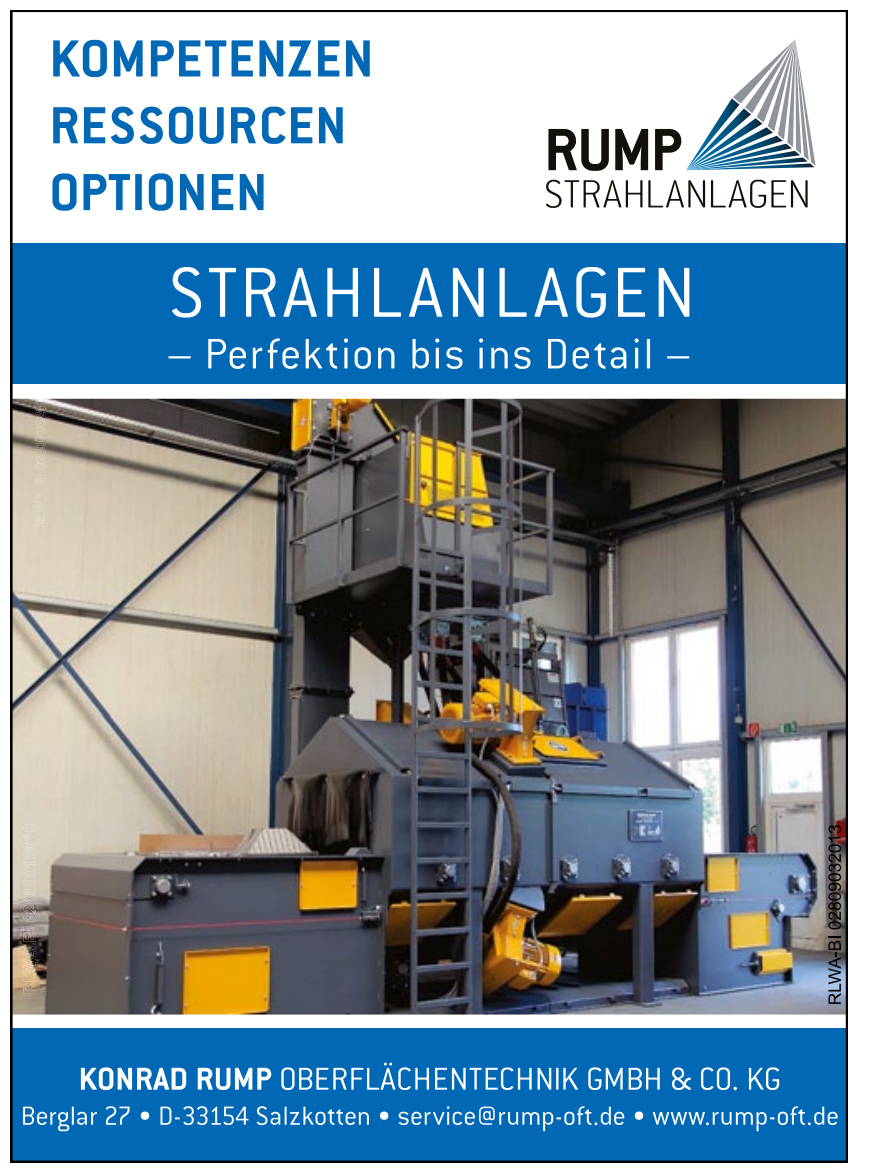

